ARID International Journal for Science and Technology (AlJST)

ISSN: 2662-009X

Journal home page: http://arid.my/j/aijst

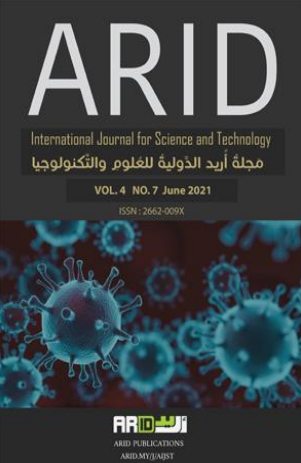

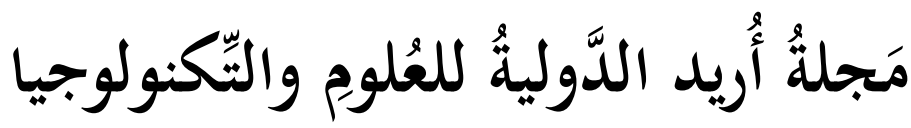

$$
\begin{aligned}
& \text { العدد } 7 \text { ، البحلد } 4 \text { ، حزيران } 2021 \text { م }
\end{aligned}
$$

\title{
Clinical study to eVAluate The Retention OF lOWer COMPLETE DENTURES WITH DIFFERENT TECHNIQUES
}

\author{
NARIMAN YASSIN MARAKA
}

DePartment of Removable Prosthodontics. FACUlty of Dentistry. HAMA UniVERSity, HAMA, SYRIA

$$
\begin{aligned}
& \text { دراسة سريرية لتقييم ثبات أطقم الأسنان الكاملة السفلية بتقتيات مختلفة }
\end{aligned}
$$

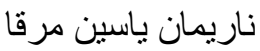

$$
\begin{aligned}
& \text { قسم التعويضات المتحركة ـ كلية الأسنان - جامعة حماهـ حماه - سوريا }
\end{aligned}
$$$$
\text { dr.nmaraka@gmail.com }
$$$$
\text { arid.my/0005-6196 }
$$

https://doi.org/10.36772/arid.aijst.2021.472 


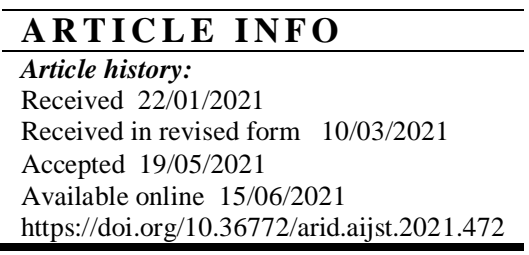

\begin{abstract}
The retention of the lower denture, was one of the most important factors for success the complete dentures (CD) for edentulous patients with resorbed mandibular ridge. Therefore, this study was conducted to compare the retention of the lower complete denture for patients with full resuscitation treated by traditional complete denture and denture manufactured by silicon materials. The studied sample consisted of (12) patients (5 males and 7 females) between the ages of (55-71) years, with an average age of (63) years. Two lower dentures were made in two different ways: the conventional method and the silicon material method opposite to one upper whole denture. The retention of the lower denture was measured on the digital forces meter when the dentures was delivered to the patient. Three readings were recorded for each technique.

The results showed a difference in the retention of the lower denture. The retention value by Newton (N) In set of lower manufactured using silicon materials of the lower denture were (7.03) higher in the set of lower denture manufactured in the traditional way.
\end{abstract}

Keywords: adsorbed alveolar mandibular ridge, $\mathrm{CD}$, conventional method, silicon material, retention of dentures. 


\section{الملخص}

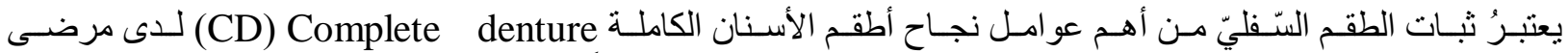

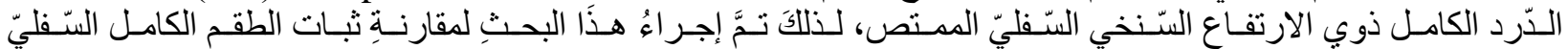

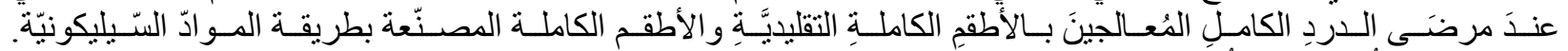

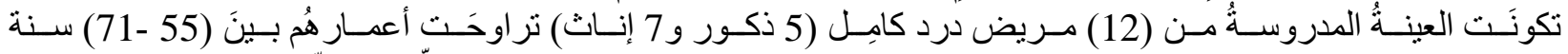

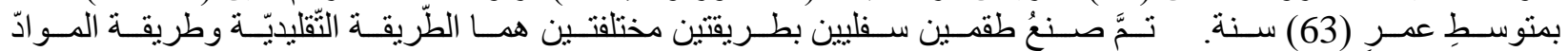

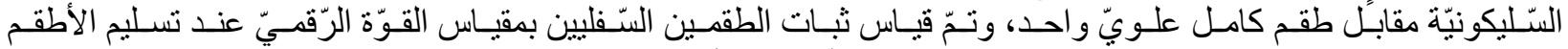

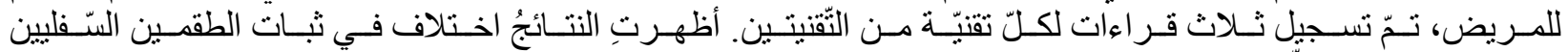

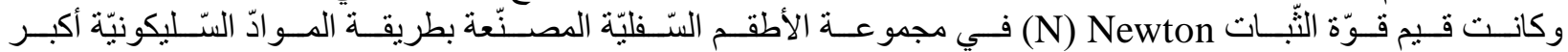
بمقدار 7.03 منها في مجمو عة الأطقم السّقليّة المصنّمة بالطريقة التقّليديّة.

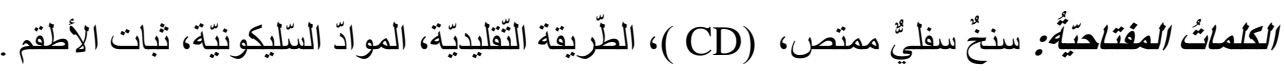


إن تأمين ثبات CD يعتبر أحد أهم أهداف المعالجة التّعويضيّة عند مرضى الدّرد الكامل و الهدف من طبّ الأسنان تعويض المريض عن الناحية الجمالية والوظيفية وتحسين الناحية الصّحية انطلاقاً من إزالة النخر حتى التعويض عن الأسنان المفقودة [1]. هذا وتعتبر الأطقم الكاملة المتحركة أجهزة ميكانيكية رئيسية تؤدي وظيفتها في الحفرة الفموية وارتداء هذه الأطقم يتناسق

ويتلاءم مع وظائف الجملة العصبية العضلية وقد يكون له تأثير معاكس على الصحة الفموية والنسج الداعمة للجهاز [2]. كما أن نجاح CD يعتمد على تأمين الخصائص الثلاثة (الثبات والاستقرار و الدعم) حيث تظهر الأطقم السّفليّة الكاملة للأسناخ الممتصّة صـعوبة في تحقيق هذه الخصائص بسبب القيود التشريحية وتأثر ثباتها بعو امل عديدة منها: الالتصاق، اللزوجة، الضغط الجويّ، العوامل الخارجية الناشئة عن عضلات الفم و الوجه [3].

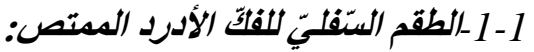

يشكل تحديات تقنية كبيرة لطبيب الأسنان و أحياناً تطرح تحدي مهم للمريض ومع ذلك فإن المبادئ الأساسية لطبعات الطقم السفلي مشابهة لتلك الخاصة بالطقم العلوي. إن كل من مناطق الدعم والمنطقة المحيطية أو المنطقة الحدية ستكون بتماس مع سطح الطبعة أو مع الطقم المناسب المنطبق يجب أن تمتد قاعدة الطقم السفلي أبعد ما أمكن دون تداخل مع صحة أو وظيفة الأنسة. يأتي دعم الطقم السفلي من جسم الفكك السفلي ويتأمن الختم المحيطي من شكل حواف الطقم المحدد بالمناطق التشريحية الوصفية. كما أن وجود اللسان وحجمه وحركته تصعب من إجراءات أخذ طبعة الطقم السفلي ويقلل من ثباته[4]. 2-1 2-1 تقسم العضلات التي تحيط بالطقم إلى مجمو عتين منفصلتين: ـ العضلات المزيحة للطقم: التي تؤدي إلى إزاحة الطقم من موضعه الصحيح خلال عملها. ـ العضلات المثنتّة: التي تعمل على تثبيت الطقم في موضعه بوساطة الضغط المطبّق على السطوح الملمعـة. كما ويمكن تقسيم هذه العضلات وفقاً لموضعها بالنسبة للطقم إلى: ـ دهليزية (شفوية وخدية) - لسانية[3]. 3-1

1-3-1

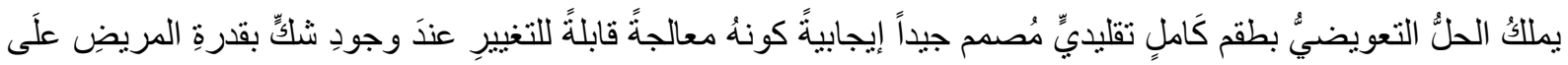

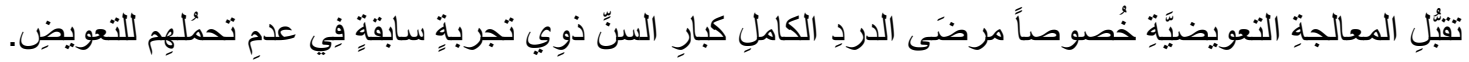




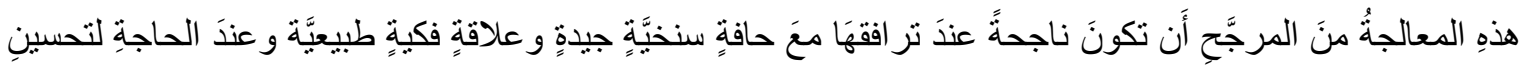
الوظيفةِة أَو الناحيَة التجميليَّةِ للمريضِ.

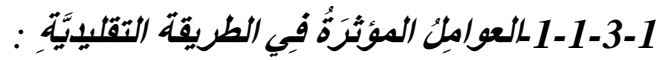

تحتاج هذه الطريقة خِبرةٌ سابقَةٌ جيدةٌ عند تصميم و تصنيع الأَطقم الكاملَة، و استقر ارٌ كافٍ يتعلق بشكلِ السَنخ ونتميز بالمعالجَة

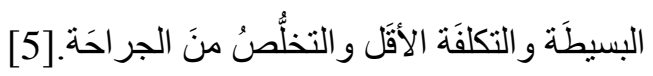

\section{}

إنخفَاض قوَّة العَض Bite force مِن (200-50) باو ند/ إنش،فبعد خمس عشرة سنة من استخدام الأطقم التقليدية تنخفض قوَّة

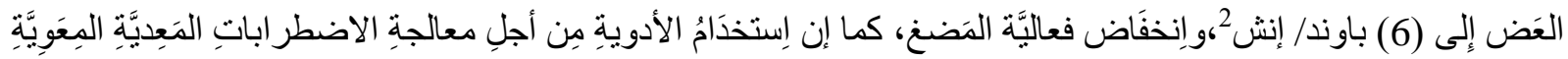
المتشكِلَة ومحدوديَّة فِي اختيارِ الأطعمَة، و إِخفَاض فِي كميَّة الأغذيَّة الصحيَّة المتناولَة [2]. يستخدم في الطبعة النهائية بالطريقة التقليدية معجون الطبع (IP) Impression Paste مع طبعة حواف بمركب الطبع الأخضر العصا الخضر اء بوضعية الفم المفتوح[6] و عندما تصبح الحافة السنخية الممتصة غير قادرة على تأمين الدعم وسببث انزياح الجهاز بالطريقة التقليدية و النتيجة لم تعد مرضية كان لا بد من إجر اء التعديلات على الطبعات، فكانت الطرق الآتية للتغلب على هذه السلبيات: الطّريقة المركّبة [7]، طريقة مركّب الطّبع الأخضر [8]، طريقة الطّبعة الوظيفيّة و الفم مغلق[9]، طريقة الكوكتيل[10]' طريقة الموادّ السّليكونيّة [11] ـ تقنيات الطبعات هذه تتمتع بالصفات التالية: يمكن التحكم بسهولة للحصول على أقصى حد من التغطية، يمكن تصحيحها بسهولة، يمكن استخدامها بدقة وتحديد انطباعات الأغشية المخاطية، يمكن استخدامها للضغط المباثر للمناطق الحاملة و السفوح المتبقية للارتفاع السنخي السفلي[12]. 2-3-1

طبعة المو اد المرنة ( المطاط ) تؤخذ بها الطبعة النهائية حيث يتم استخدام درجة لاصقة على الحدود داخل وخارج السطح الاكريلي للطابع الإفر ادي ليسهل ثبات السليكون (إضافة المادة السليكونية) وهي المسماة فينيل بوليسيلوكسان حراري لوني للتشكيل الأول للطبعة مع ثبات نهائي مرن يزيد من زمن العمل في الفم، يوضع الطابع في الفم ويطلب من المريض تحريك لسانه وفقا لمعايير الانطباع. نز ال الطبعة ويطبق الفينيل ذو اللزوجة المنخفضة للحصول على الدقة العالية للنسج مع وقت Murray سريع في الصلابة[11]. وُجدت در اسات كثيرة درست تقنيّة الطّبعات وتأثنير ها على ثبات الأطقم، ناقش الباحثين 1993 and Darvell 
يحدث فيها انزياح الطقم، بالنسبة للأفر اد امتصاص العظم وحدته تجعل الحصول على الثبات الجيد والاستقرار الكامل صعب لوجود العضلات بالقرب من قمة السنخ حيث سجلت التقنية الوظيفية أعلى قيمة لها من حيث متوسط الثبات. وجد الباحث 2005 Winkler تدخل الطبيب في الحركات. كما أن وينكلر وجد عيوباً لهذه التقنية:لا يتحكم طبيب الأسنان في حركة المريض التي قد ثُتنج حدود ناقصة أو مفرطة ،مثل حركة اللسان الأمامية التي قد تغير وتثوه الحواف اللسانية للطق. وجد الباحث Smith وزملائه 1979 [14]أن تقنية المواد المرنة سجلت ثاني أعلى قيمة لها في دراسة سابقة وتمتعت هذه التقنية بمز ايا وهي: أخذ حدود الطقم في خطوة واحدة و الحركة الوظيفية للمريض كانت تتم أثناء أخذ الحدود ووجد أنّ المريض لا يتحمل الحر ارة الناجمة عن مركبات الطبع.

- كما أن الباحث Tan وزملائه 1996 [15] وجدوا أن مو اد البولي فينيل سيلوكسان تتطلب وقتاً أقل لأخذ حدود

الأطقم مقارنة مع الطريقة التقليدية.

وجد الباحث Applebaum وزملائه 1984 [11] أن المعجون الرخو هو المادة المناسبة لأخذ كامل انطباعات الفك السفلي وتحقق نتائج أفضل ووقت أقل و أقل إز عاجا للمريض والطبيب وكذلك فني الأسنان. - ـ وجد الباحث Praveen وزملائه 2011 [10]أن تقنية الكوكتيل تلغي عيوب وينكلر من إصابته بتأثر خلع العضلات على امتداد الطقم بشكل غير صحيح و الاستفادة الكاملة من تثبيت الأنسجة الإيجابي والسلبي للأسنان. و الفلك السفلي يقع في علاقة مناسبة مع الفك العلوي لتحقيق الاستقرار في علبة مخصصة ومنع النزوح الأفقي للطابع أثناء الانطباع النهائي. ومن ميزات هذا الطابع الذي يؤدي مباشرة إلى تشكيل مادة الطبع بحركات وظيفية ومن قبل العضلات ومجاور اتها من النسج على حدود قاعدة الطقم.

كما بين كلاً من الباحثين 1997 Mccord and Tyson [7 ضرورة استخدام تقنية الطبعة المركبة للانطباعات السنخية الضامرة، ووجد ميزة تسجيل موقف وظيفي للعضلات في خطوة واحدة ووقت قصير وكلفة أقل مقارنة مع مكيف الأنسجة أو مادة التبطين. ووجد الباحث Petrie وزملائه 2005 [16] أن الطريقة التقليدية باستخدام مركب الطبع الأخضر و أكسيد الزنك و الأوجينول هي المو اد الأكثر شعبية للحصول على الانطباع الكامل، حيث وجدوا: إعدادها سريع استتساخ التفاصيل الدقيقة وسهلة التعامل مع عدم وجود تغير ات مهمة في الأبعاد بعد التصلب، ومساو ها كانت: وقت عمل قصير وتصلب سريع. - وجد الباحث Yadav وزملائه 2014 [17] في در اسة له أن الطريقة التقليدية أظهرت أقل قيمة ثبات مقارنة مع خمس طرق أخرى بينما احتلّت طريقة الموادّ السليكونيّة المرتبة الثّانية فيها. 
ـ دعى الباحث Tan وزملائه ببداية 2009 [18]إلى استخدام الانطباع الوظيفي باستخدام المو اد المرنة (السيليكونية) التي تحد هذه الطريقة من الطريقة التقليدية. الكهف من البحث: هو مقارنة ثبات الأطقم الكاملة السفلية بالطريقة التقليدية وطريقة المو اد السيليكونية عند مرضى الدرد الكامل، الّذين يعانون من نقص ثبات الطقم السّقليّ بسبب الامتصاص السّنخيّ. 2- 2

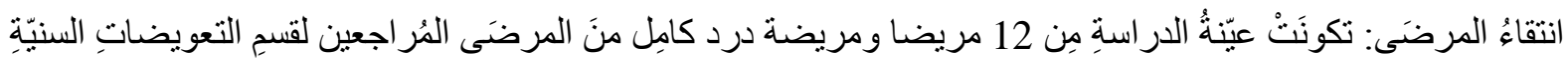

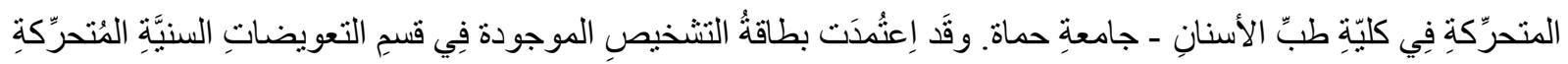

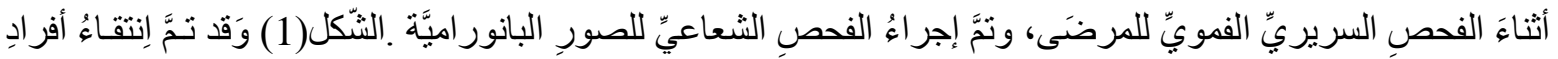

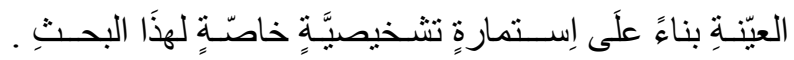
وفقاً لتوافُرِ معاييرِ الإدخال التاليةِ:

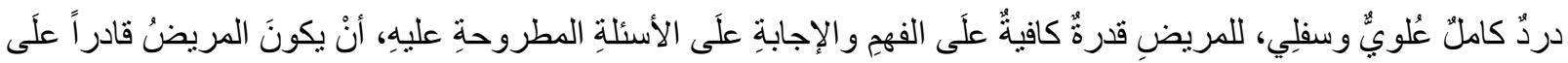

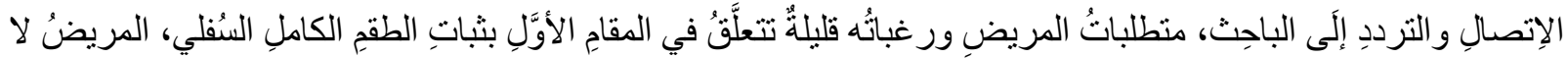
يستطيحُ تحمّل المعالجةٍة بالزّر عات. المريضُ على علع بالبحثِ و الموافقةُ قد أخذت منهُ .

\section{1-2 المرحلُة التعوبينَيَّة (صنعُع الأطقم الكاملَة):}

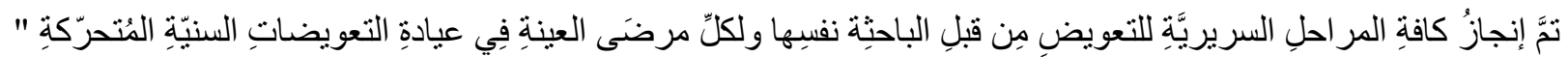
الدراسَات العُلبا"، كليَّةُ طبِّ الأسنانِ - جامعةُُ حماة .

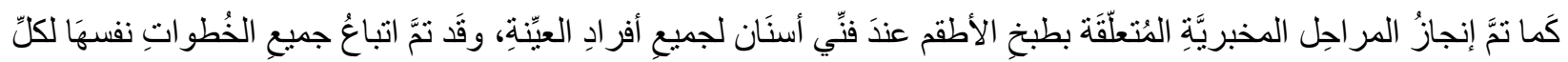
مرضنَى العينَة.

2-2-2

فلك سفلي أدرد _ الثكل (2) - .

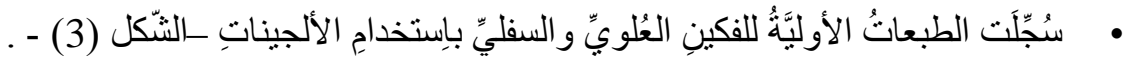




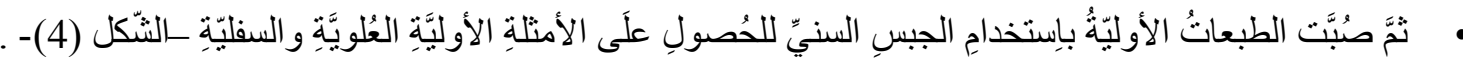

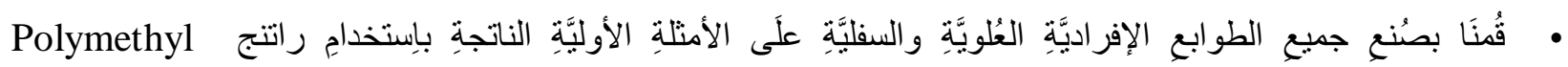
(5MMA) methacrylate • بحيث حصلنا على طابعين إفر اديين سفليين تمّ صنعهما على نفس المثال الجبسيّ الأوليّ .

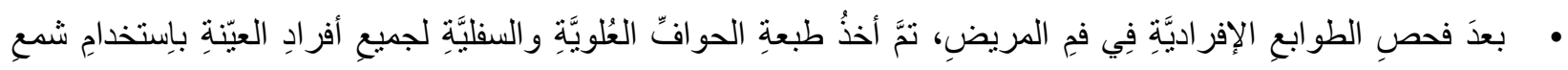
الحَو افِ Kerr للطّريقة التّقليديّة_الثَّكل(6)- .

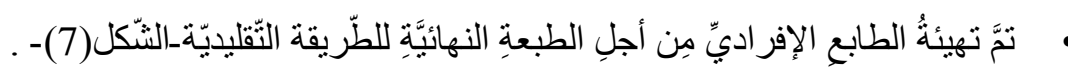

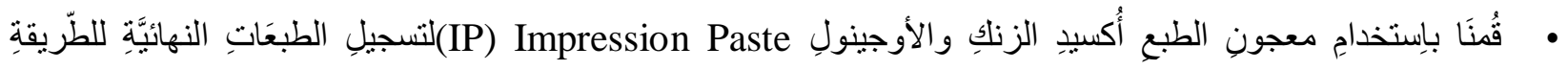

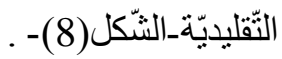

بالنّبنةِ لطريقةٌ المو ادِّ السّيليكونيّة: تؤخذ طبعة الفكّ السّقليّ كالآتي: • يطّيق التّلاصق على حدود الطّابع الإفر اديّ من الدّاخلِ و الخارج لتأمين ثبات مادّة الطّبع مع الطّابع الإفر اديّ. • مّّ تطبيق المادّة السليكونية المرتفعُة اللّزوجة لأخذ طبعة الحوافّ ويطلب من المريض إجراء كامل الحركات الوظيفيّة وشّد

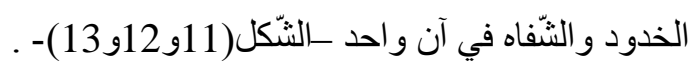
• بعد ذلك تطبق المادّة السليكونية المنخفضة اللّزوجة باستخدام جهاز خاص لحقن المادّة وفق معايير ثابتة ـالثّكل(14)- . • يتمُ الحصولُ على طبعتين نهائيتين سفليتين بطريقتين مختلفتين مع طبعةٍ علويّةٍ واحدة .

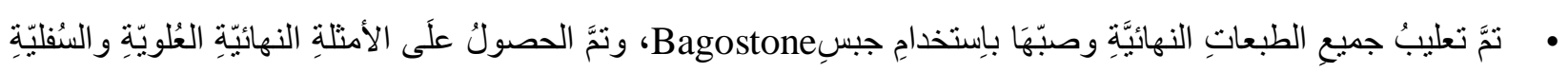

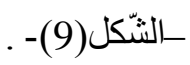

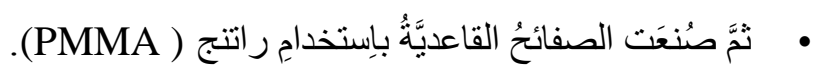

$$
\begin{aligned}
& \text { • وَقُمنَا بصنع الإرتفاعاتِ الثمعيَّةِ ـالثنّكل(17و18)- . . }
\end{aligned}
$$

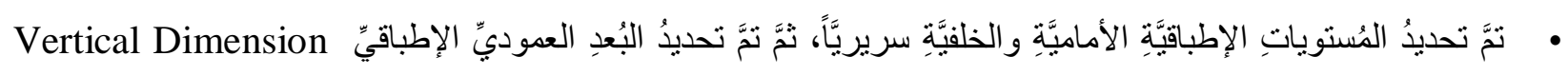
. -الثنّكل(19)(VDO) Occlusion

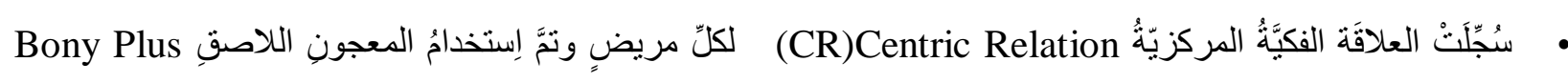
مِن أجلِ تثبيتِ الصفائح القاعديَّة أثناءَ أخذِ العلاقِة المركزيَّة. 


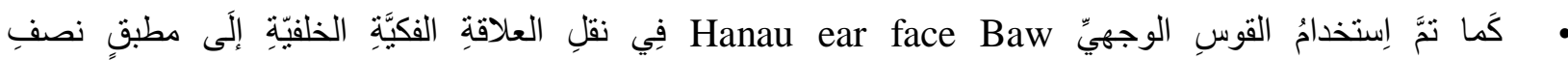

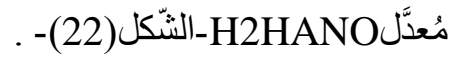

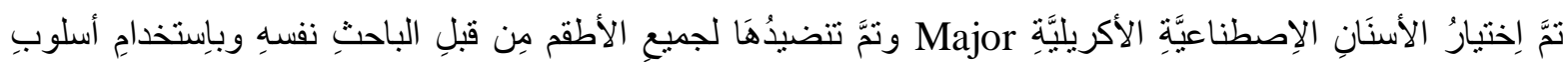

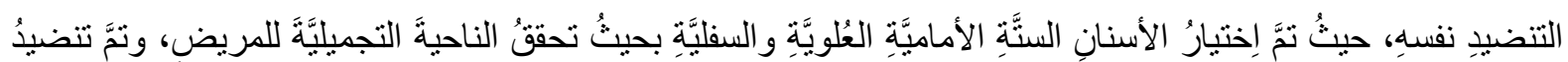
الأسنانِ الخلفيّةِة بالإطباقِ المُتو ازنِ ثُنائيِّ الجانِب_الثّّكل(24)- .

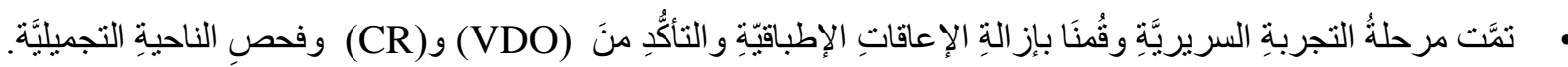

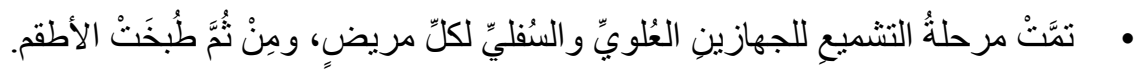

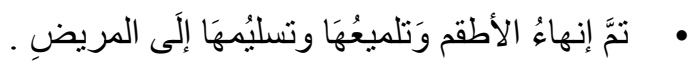

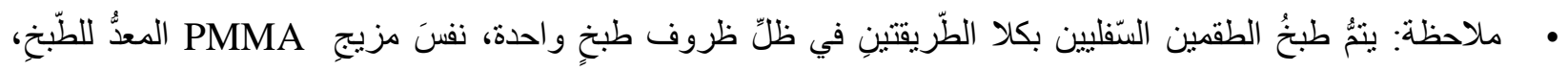

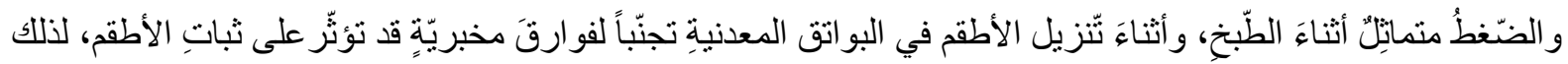

$$
\text { تمّ توحيد شروطِ إعداد الأطقم. }
$$

3-2قياس ثبات الأطقم: يتمّ بعدها فحص الدّعم والثّات و الاستقر ار لكلا الطقمين في فم المريض للمقارنةِ بينَ الأطقم. تمَّ استخدام مقياس القوّة الرّقميّ الَّني استخدمه الباحث Burns وزملائه 1995 [19] حيث يوضعُ المريضُ على الكرسيّ السّنّيّ و ظهرهُ على استقامة و الرّأس مشدود إلى مسندِ الكرسيّ. يوضحُ الطقم السّفليّ في فِّ المريضِ يوضعهِ الصّحيحِ و اللسان في

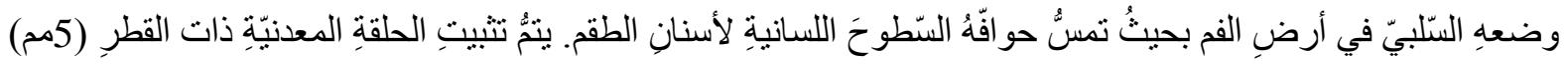

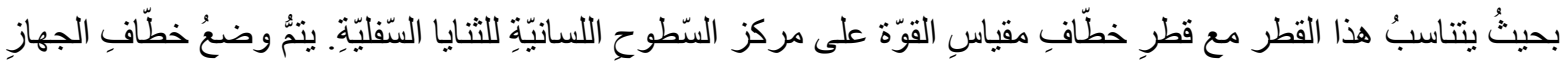

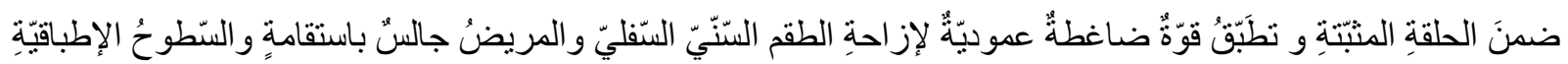

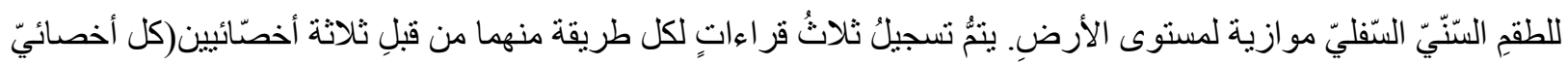

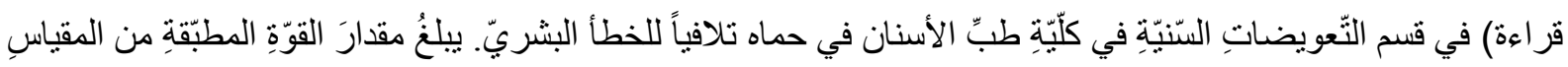

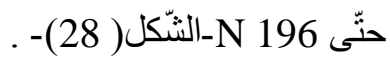




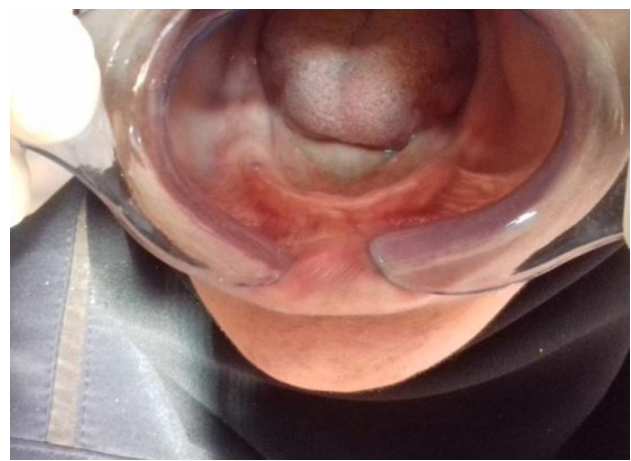

الثكل(2): فلكّ سفليّ

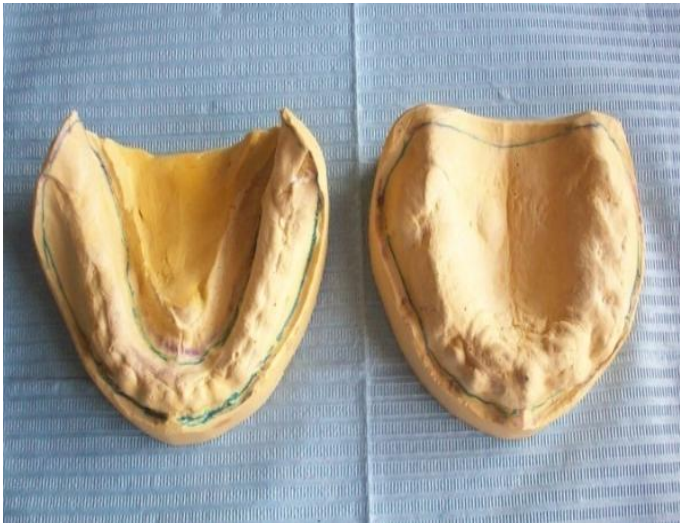

الثكل(4): الأمثلة الأوليّة

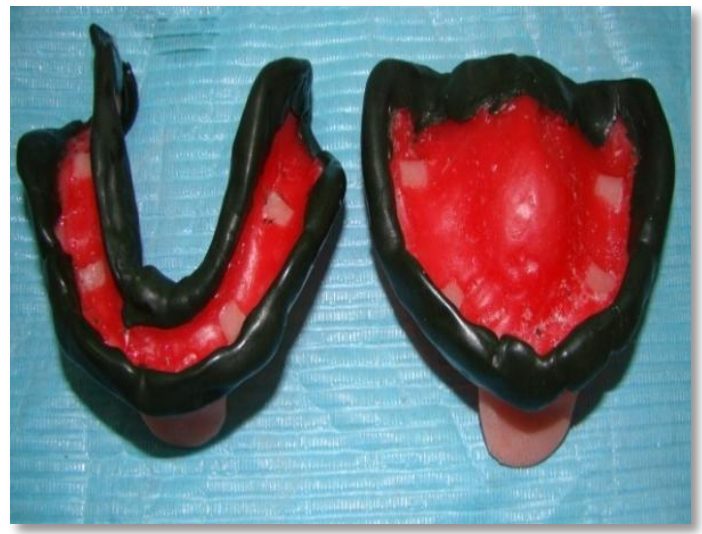

الثكل(6): طبعة الحواف بالطّريقة التّقليديّة

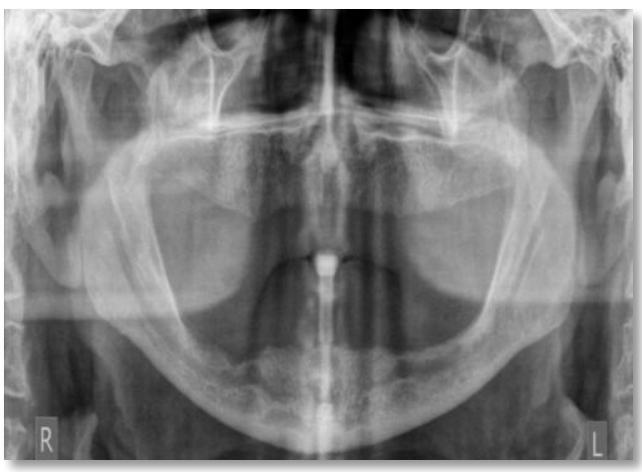

الثّكل(1): مورة شعاعيّة

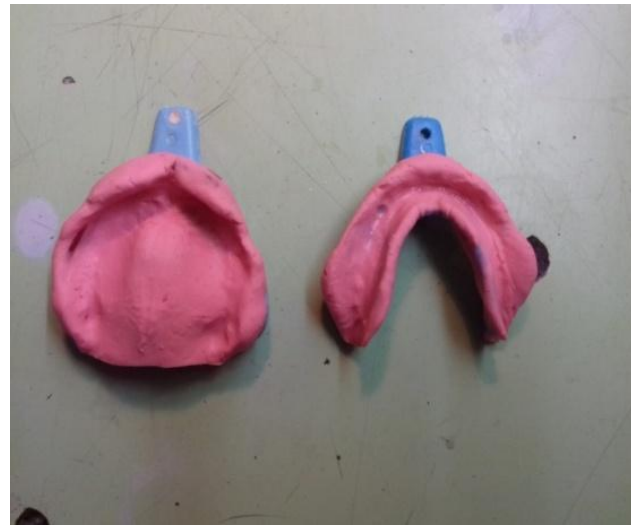

الثّكل(3): الطبعات الأوّلية

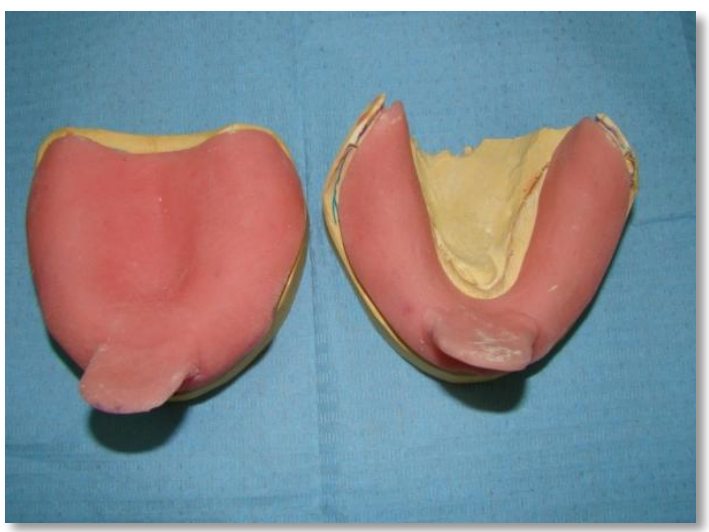

$$
\text { الثنّكل(5): الطو ابع الإفراديّة }
$$




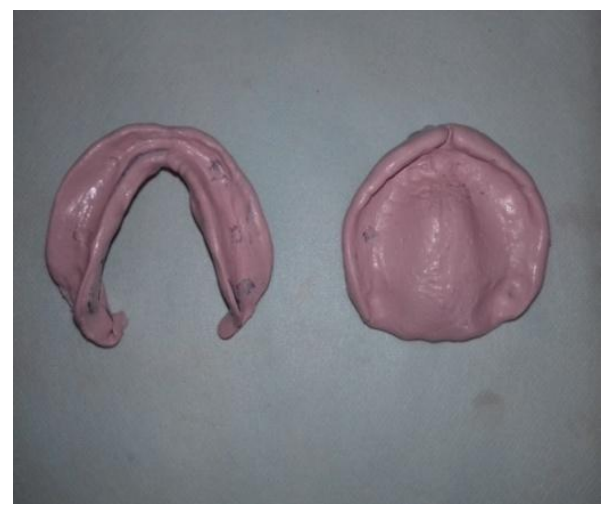

الثّكل(8): الطّبعة النّهائية للطّربقة التّقليديّة

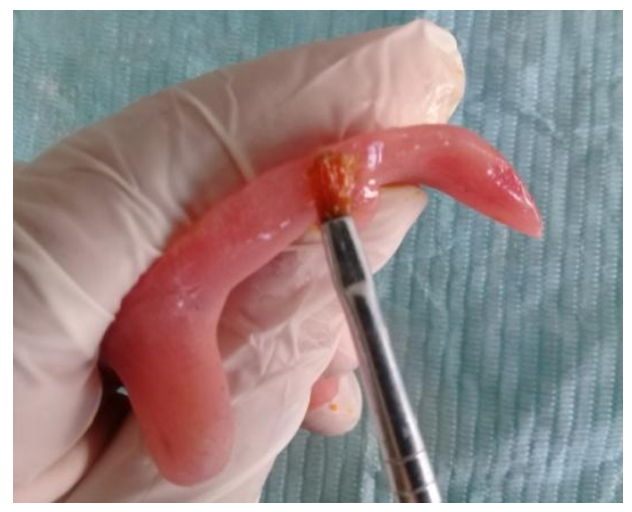

الثّكل(10): تطبيق لاصق المادّة السّليكونيّة

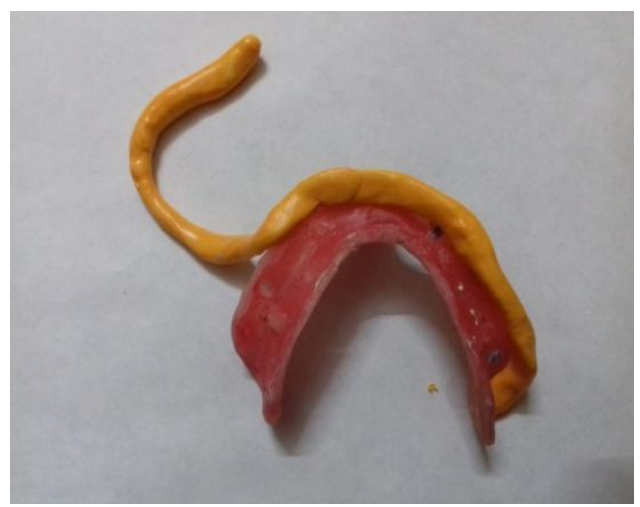

$$
\text { الثّكل(12): تطبيق المادّة مرتفعة اللزوجة }
$$

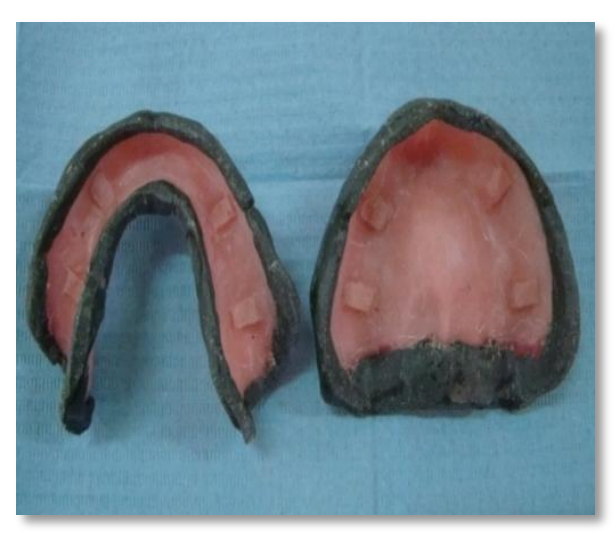

الثّكل(7): تهيئة الطّو ابع للطّريقة التّقليديّة

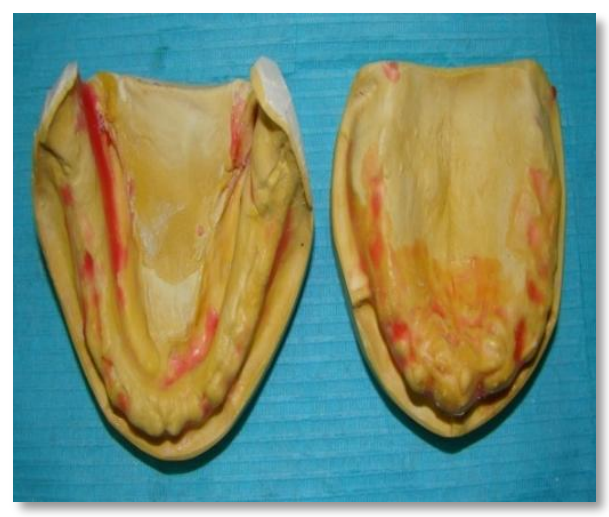

الثَكل(9): الأمثلة النّهائيّة للطّريقة التّقليديّة

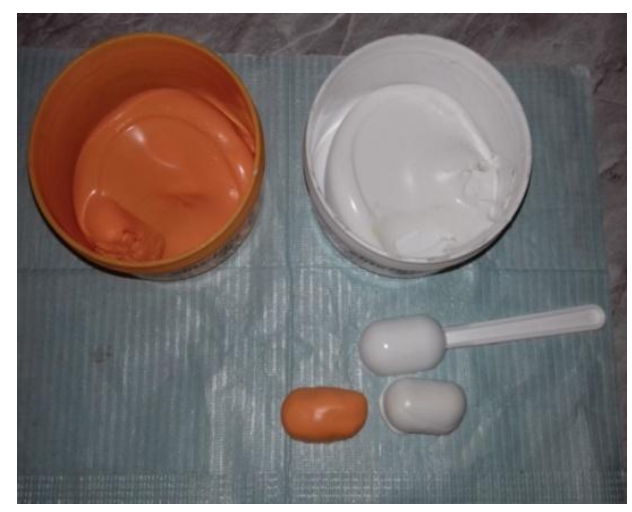

الثنّكل(11): كمّيتان متساويتان من الموادّ السّليكونيّة 


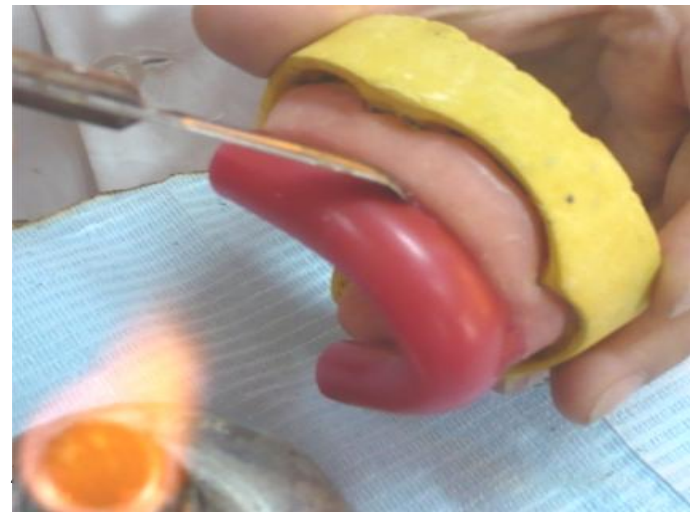

الثّكل(16): صنع الارتفاع الثّمعيّ

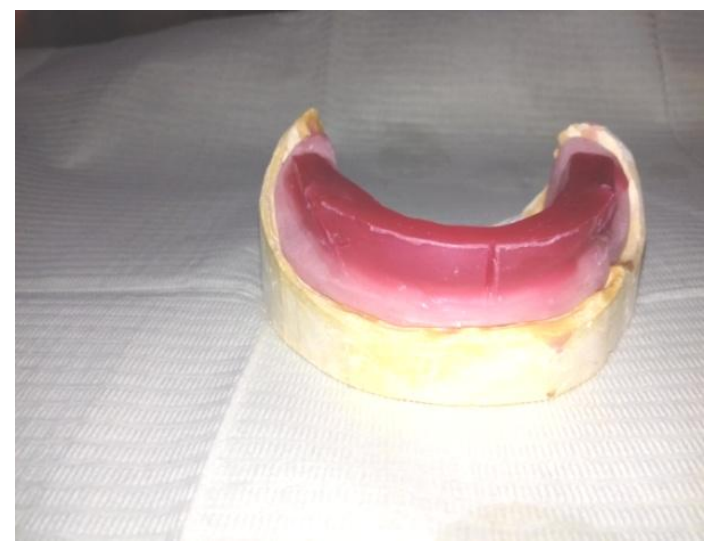

الثَّكل(18): الصّفيحة مع الارتفاع الثّمعيّ

بطريقة الموادّ السّليكونيّة

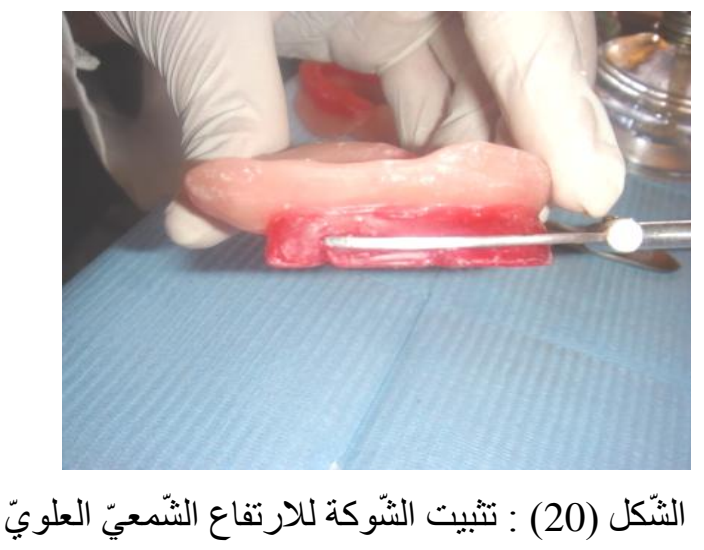

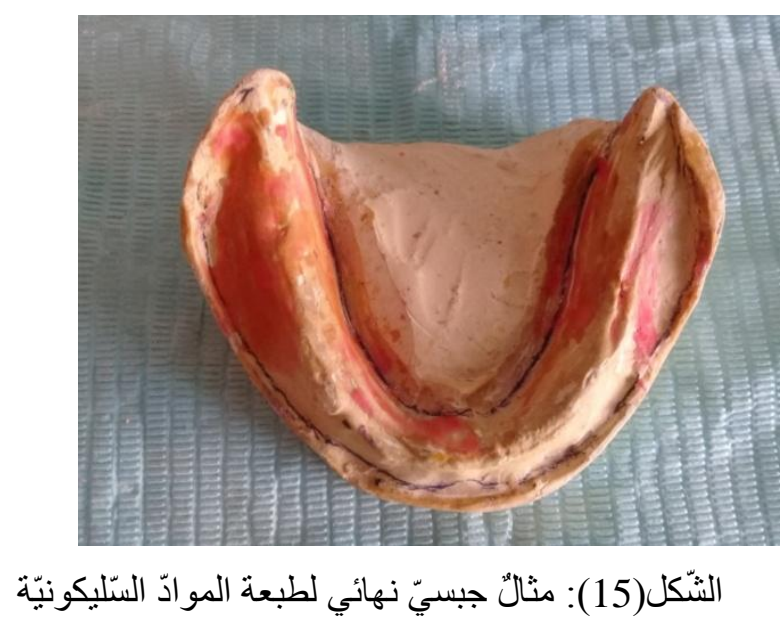

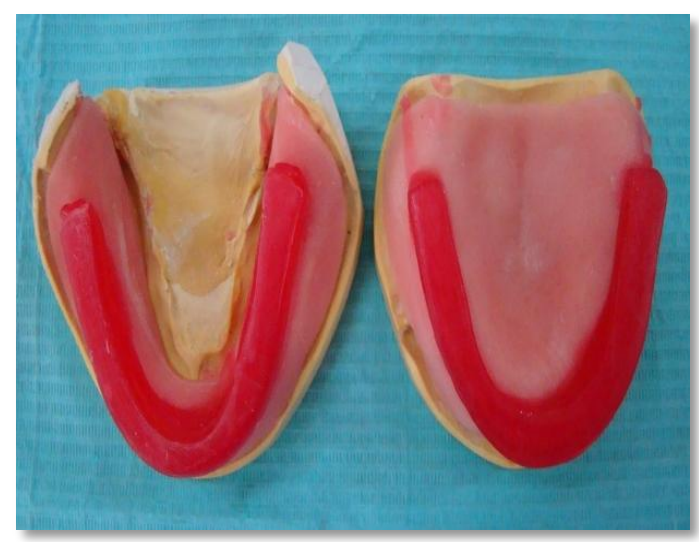

الثّكل(17): الصّفائح مع الارتفاعات الثّمعية بالطرّيقة التّقليديّة

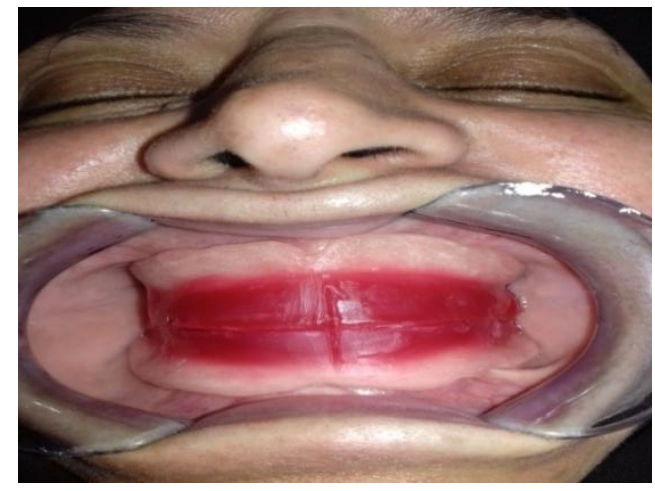

الثّّكل (19) : تسجيل العلاقة الفكيّّة 


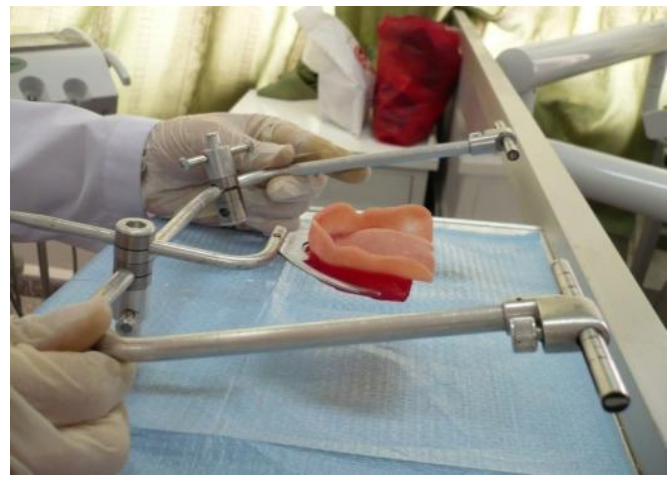

الثّكل(22): نقل العلاقة باستخدام القوس

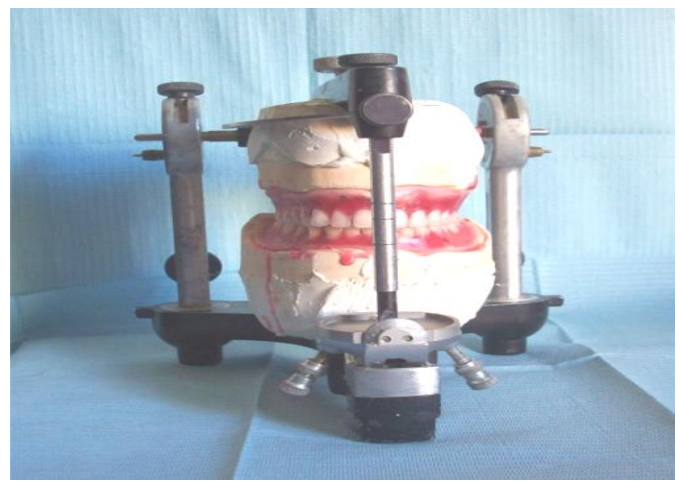

الثنكل(23): تثبيت الأمثلة في مطبق هانو

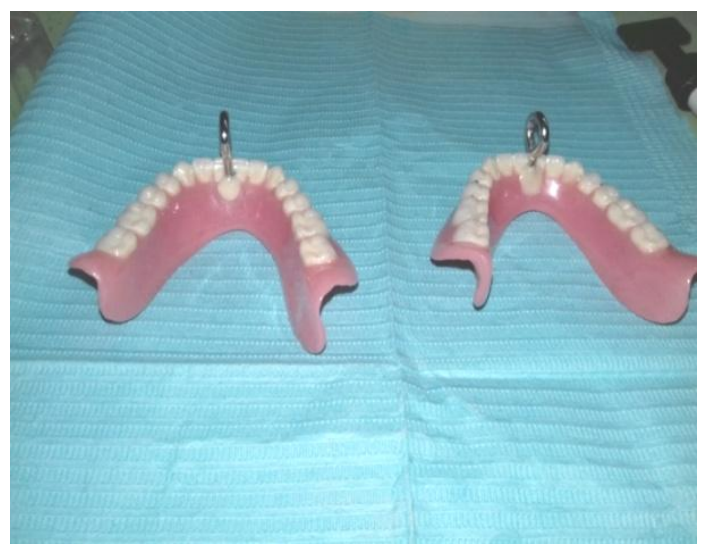

الثّكل(26): تثبيت الحلقات المعدنيّة للطقمين السّفليين

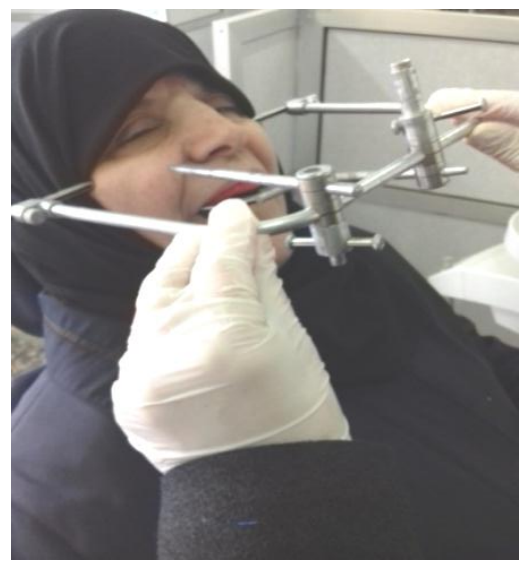

الثّكل(21) أ: نقل العلاقة باستخدام القوس الوجهيّ

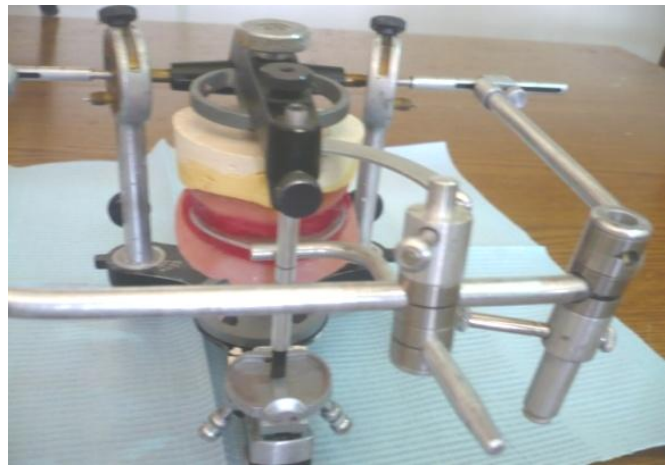

الثّكل(24): ت التضيد الأسنان

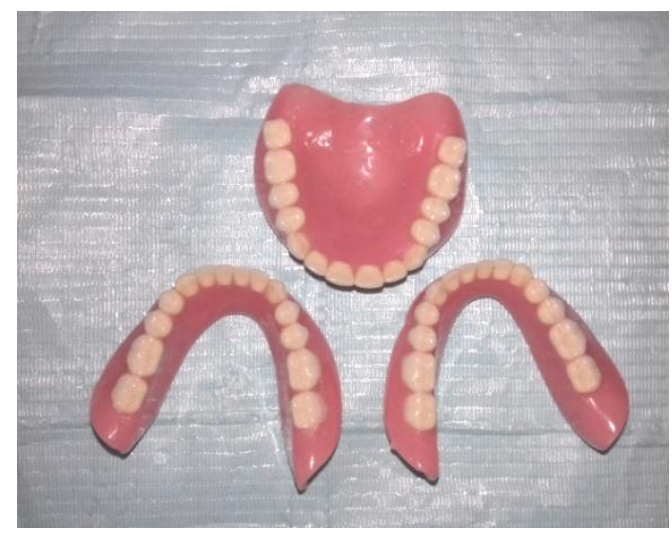

الثّكل(25): طقمين سفليين مقابل جهازٍ واحدٍ علويّ 


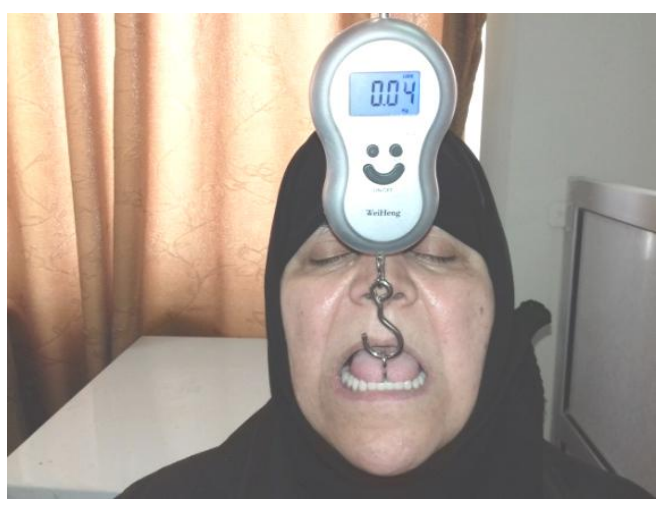

الثنّكل(28): قياس ثبات الطقم

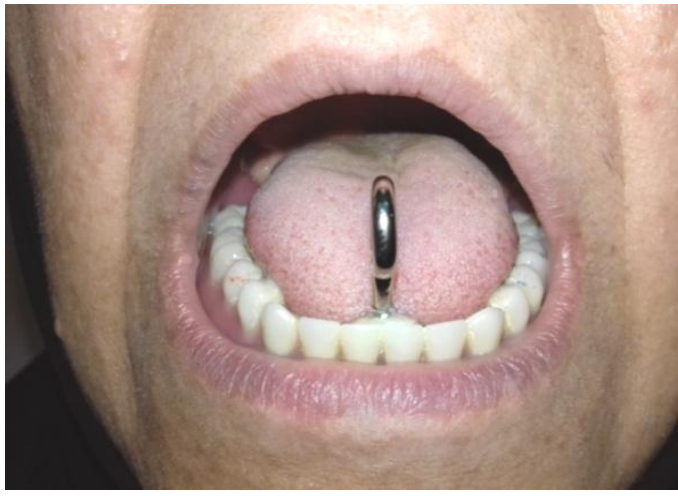

الثُّكل(27): وضع الطقم مع الحلقة في فم المريض

3 - 2 - الدّراسة الإحصائيّة:

\section{ـ دراسة تأثير طريقة تصنيع الطقم المتبعة في قبيم مقدار قوة الثبات في عينة البحث:}

تم إجر اء اختبار T ستيودنت للعينات المستقلة لدر اسة دلالة الفروق في متوسط مقدار قوة الثبات (N) بين مجمو عة الأطقم السفلية المصنّعة بطريقة المو ادّ السيليكونية ومجموعة الأطقم السفلية المصنّعة بالطريقة التقليدية في عينة البحث كما يلي: - إحصاءات وصفية: جدول رقم (1) يبين المتوسط الحسابي و الانحر اف المعياري و الخطأ المعياري والحد الأدنى و الحد الأعلى لمقدار قوة الثبات (N) في عينة البحث وفقاً لطريقة تصنيع الطقم المتبعة. جدول(1): يبين المتوسط الحسابي و الانحر اف المعياري و الخطأ المعياري

\begin{tabular}{|c|c|c|c|c|c|c|}
\hline \multicolumn{7}{|c|}{ المتغير المدروس = مقدار قوة الثبات (بالنيونن) } \\
\hline الحد الأعلى & الحد الأدنى & المعياري & المعيار الانحر اف & الحسابي & الأجهزة & طريقة تصنيع الجهاز المتبعة \\
\hline 14.27 & 8.92 & 0.37 & 1.27 & 11.43 & 12 & جهاز سفلي مصنّع بطريقة الموادّ \\
\hline 5.39 & 3.20 & 0.20 & 0.69 & 4.40 & 12 & جهاز سفلي مصنّع بالطريقة التقليدية \\
\hline
\end{tabular}




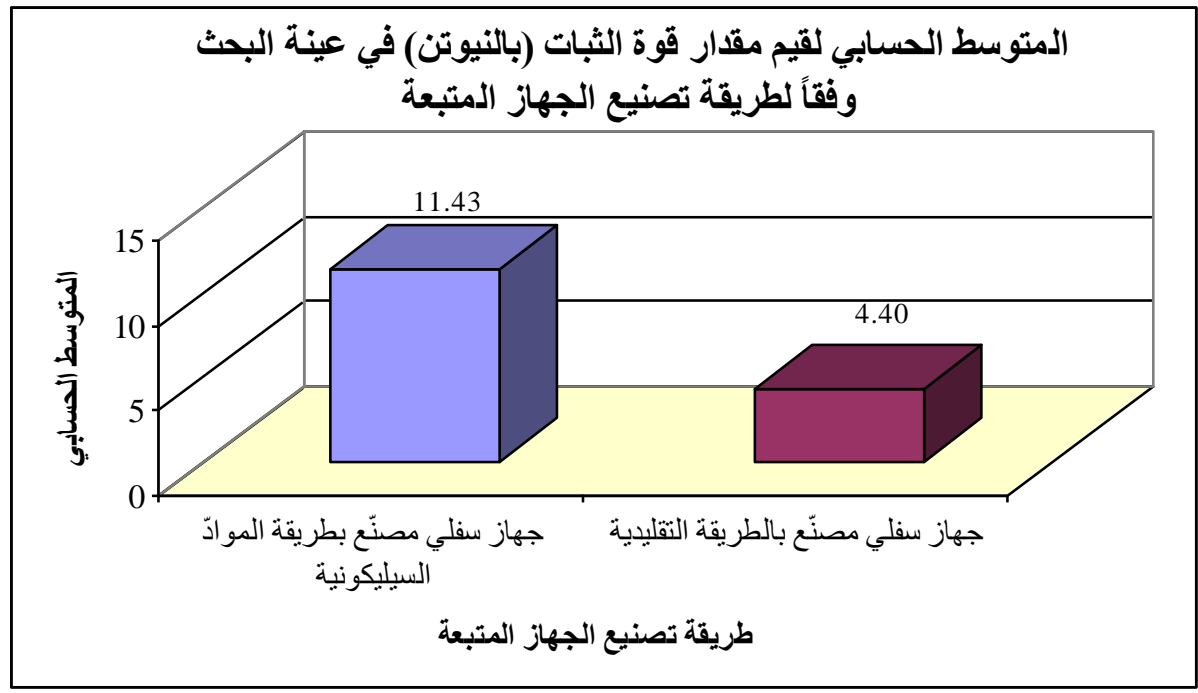

مخطط رقم (1): يمثل المتوسط الحسابي لمقدار قوة الثبات (N) في عينة البحث وفقاً لطريقة تصنيع الطقم المتبعة.

\section{- نتائج اختبار T ستيودنت للعينات المستقلة:}

جدول رقم (2) يبين نتائج اختبار T ستيودنت للعينات المستقلة لدراسة دلالة الفروق في متوسط مقدار قوة الثبات (N) بين مجمو عة الأطقم السفلية المصنّعة بطريقة المو ادّ السيليكونية ومجموعة الأطقم السفلية المصنّعة بالطريقة التقليدية في عينة البحث.

جدول(2): يبين نتائج اختبار T ستيودنت للعينات المستقلة

\begin{tabular}{|c|c|c|c|c|c|}
\hline \multicolumn{6}{|c|}{ المتغير المدروس = مقدار قوة الثبات (N) } \\
\hline دلالة الفروق & قيمة مستوى الدلالة & الخطأ المعياري & الفرق بين & الحرية & المحسوبة t \\
\hline توجد فروق دالة & 0.000 & 0.42 & 7.03 & 22 & 16.838 \\
\hline
\end{tabular}

يبين الجدول أعلاه أن قيمة مستوى الدلالة أصغر بكثير من القيمة 0.05، أي أنه عند مستوى الثقة 95\% توجد فروق دالة إحصائياً في متوسط مقدار قوة الثبات (N) بين مجموعة الأطقم السفلية المصنّعة بطريقة المو ادّ السيليكونية ومجمو عة الأطقم السفلية المصنّعة بالطريقة التقليدية في عينة البحث، وبدر اسة قيم المتوسطات الحسابية نستتتج أن قيم قوة الثبات في مجموعة الأطقم السفلية المصنّعة بطريقة الموادّ السيليكونية كانت أكبر منها في مجموعة الأطقم السفلية المصنّعة بالطريقة التقليدية في 
هذه الدراسة هي دراسة تطلعية سريرية لتقييم ثبات الأطقم الكاملة السفلية لمرضى الدرد وتأثير تقنية الطبعة النهائية المستخذمة و المقارنة بينهما. إن تأمين ثبات CD يعتبر أحد أهم أهداف المعالجة التّعويضيّة عذد مرضى التّرد الكامل والهدف من طبّ الأسنان هو تعويض المريض عن الناحية الجمالية والوظيفية وتحسين الناحية الصّحية انطلاقاً من إزالة النخر حتى التعويض عن الأسنان الدفقودة[1] .و استخدمنا طريقة المو اد السيليكونية (فينيل بوبي سيلوكان) الطابعة المعروفة بالسيليكون بتفاعل الإضافة لأنها أصبحت واسعة الانتشار خلال السنوات الأخيرة[20] ولقد استخدم النوع منخفض اللزوجة لهذه المادة عبر جهاز الحقن (المزج الآلي) بدلاً من المزج اليدوي وذلك للأسباب الآتية:

تمازج لوني جيد للأساس والمسرع، إدخال كمية هواء أقل إلى المزيج، إنقاص زمن المزج، احتمال تلوث أقل للمادة الطابعة[21] وتم استخدام الطريقة التقليدية للمقارنة مع طريقة المواد السليكونية كونها الطريقة الأكثر شعبية في دول العالم وتستخدم مركب طبع الحواف مع مركب أوكسيد الزناك والأوجينول. و التي تبدي عدم وجود تغييرات مهمة في الأبعاد بعد التصلب و استنتاج التفاصيل الدقيقة]9]. و عادة تؤخذ طبعات الحافة السنخية بالطريقة التقليدية أو طريقة المو اد السليكونية وذلك بسبب الدقة الكامنة في هذه المواد وتوزيع الضغط المتوازن[22]. وبدراسة قيم المتوسطات الحسابية نستنتج أن قيم قوة الثبات في مجموعة الأطقم السفلية المصنعة بطريقة المو اد السيليكونية كانت أكبر منها في مجموعة الأطق السفلية المصنعة بطريقة المو اد التقليدية بمقدار قدره 7.03 نيوتن.

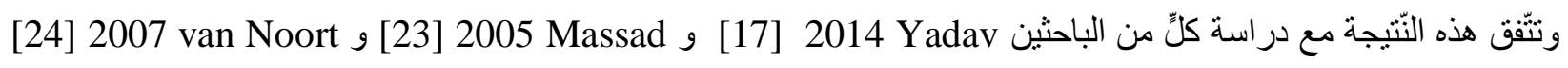
فقد أصبحت تقنية استخدام السليكون العالي ومنخفض اللزوجة منتشرة بين أطباء الأسنان وتم تطوير هذه التقنية لما لها من مزايا حيث أنها تزيد من دقة الطبعة بتغلبها على تغير الأبعاد الكبير لأن معظم التقلص الحاصل أثناء عملية التبلمر (التقلص التصلبي) يحدث في النوع مرتفع اللزوجة فقط وبالتالي تكون الطبعة أكثر ثباتاً في الأبعاد، كما أنّ طريقةَ الموادّ البّلّكونيّة تفوّتت على الطَّريقة التُقليديّة حيث إن الانطباع الوظيفيّ باستخدام السّلّكون يحدّ من استخدام مركّب طبع الحواف و IP

علماً أن الكثير من الدراسات أكدت أن العامل الأساسي لتأمين ثبات الأطق السفلية الكاملة يتحقق بالتناسق العصبي العضلي مع استخدام تقنية المنطقة الححايدة [25]. و أن التقنية التقليدية كانت أقل ثبات من تقنية الطبحة الوظيفية بمقدار N 8 [26] ـ وغالبا ما تحتاج أطقم الأسنان السفلية الكاملة ذات الأسناخ شديدة الامتصاص إلى الجمع بين تقنيتين تقنية الانطباع الوظيفي و تقتية الانطباع المركب ومع ذلك هناك حاجة لدر اسات أخرى لمعرفة التقنية الأفضل [27] . 
ضمن حدود هذه الدراسة السريرية يمكن استخلاص الاستنتاجات الآتية:

1 - أبدى ثبات الطقم الكامل السفلي بطريقة المو اد السيليكونية تفوقاً على الطريقة التقليدية لدى مرضى الدرد الكامل الذين

يعانون من مشاكل في ثبات واستقرار الطقم السفلي.

التوصيات

1 - نوصي أن تكون طريقة المو اد السيليكونية الطريقة المعتمدة في الكليات وذلك لسهولة المراحل السريرية لها وسهولة

تطبيقها من قبل الطالب.

2 - نوصي باستخدام طريقة المواد السيليكونية لتوفير الوقت لطبيب الأسنان و المريض .

المقترحات

1 - إجر اء در اسة سريرية لمقارنة ثبات الأطقم بعد فترة من استخدامها.

2 - إجر اء دراسة سريرية مشابهة مع زيادة حجم العينة للوصول إلى نتائج أكثر دقة ودراسة متغيرات أخرى (مثل فعالية

(المضغ).

جذول بالمختصرات

\begin{tabular}{|c|c|c|}
\hline CD & Complete denture & $ت$ \\
\hline N & Newton & 1 \\
\hline IP & Impression Paste & 2 \\
\hline PMMA & Polymethyl methacrylate & 3 \\
\hline VDO & Vertical Dimension Occlusion & 5 \\
\hline CR & Centric Relation & 6 \\
\hline
\end{tabular}


[1]- E.Raviv, A. Turcotte, and M. Harel-Raviv, "Short dental implants in reduced alveolar bone height", Quintessence international, 41(2010) 575-579..

[2]- G. E. Carlsson, "Clinical morbidity and sequelae of treatment with complete dentures", Journal of Prosthetic Dentistry,79(1) (1998) 17-23.

[3]- K. Shay. Treatment of an edentulous patient with a dry mouth. The Journal of Contemporary Dental Practice ,1(2000)98.

[4]- C. Whitmyer, S. J. Esposito, and S. Alperin, "Longitudinal treatment of a severely atrophic mandible: a clinical report”, J. of Prosthetic Dentistry,90(2) (2003) 116-120.

[5] -J.A. Hobkirk, R.M. Wotson, L .J. Searson, Introduction Dental Implants. $6^{\text {th }}$ ed, Elsevier Science, ( 2003) 63-79.

[6]- W. Greene J, Greene Brothers, "Clinical Course in Dental Prosthesis in Three Printed Lectures. New and Advanced-Test Methods in Impression", Articulation, Occlusion, Roofless Dentures, Refits and Renewals, Detroit Dental Manufacturing Company, Detroit, Mich, USA, 1916.

[7]- J. F. McCord and K. W. Tyson, "A conservative prosthodontic option for the treatment of edentulous patients with atrophic (flat) mandibular ridges", British Dental Journal,182(12)(1997) 469-472.

[8]-A. Tunkiwala and S. Ram, "Management of mandibular poor foundation: conventional complete dentures", Dental Practice,11(5) (2013) 34-37.

[9]-W.E.Winkler, "Re-identification methods for evaluating the confidentiality of analytically valid microdata", Statistics, 9 ( 2005) 1-14.

[10]- G. Praveen, S. Gupta, S. Agarwal, and S. K. Agarwal, "Cocktail impression technique: a new approach to atwood's order vimandibular ridge deformity", Journal of Indian Prosthodontist Society,11(1)(2011) 32-35.

[11]- E. M. Applebaum and R. V. Mehra, "Clinical evaluation of polyvinylsiloxane for complete denture impressions", The Journal of Prosthetic Dentistry,52(4) (1984) 537539.

[12]-V. C. Petropoulos and B. Rashedi, "Current concepts and techniques in complete denture final impression procedures", Journal of Prosthodontics,12(4) (2003) 280-287.

[13]- M.D. Murray, and B.W. Darvell, "The evolution of the complete denture base. Theories of complete denture retention-a review. Part 1", Australian dental journal,38(3) (1993) 216-219 .

[14]- D. E. SMITH, L. B. TOOLSON, C. L. BOLENDER, LORD, "One-step border molding of complete denture impressions using a polyether impression material", Journal of Prosthetic Dentistry,41(3) (1979) 347-351.

[15]- H.K. Tan, P.M. Hooper, and C.G, "Baergen, Variability in the shape of maxillary vestibular impressions recorded with modeling plastic and a polyether impression material", International Journal of Prosthodontics, 9(3) (1996)22.

[16]- C.S. Petrie, M.P. Walker, and K. Williams, "A survey of US prosthodontists and dental schools on the current materials and methods for final impressions for complete denture prosthodontics", Journal of Prosthodontics: Implant, Esthetic and Reconstructive Dentistry,14(4)( 2005) 253-262. 
[17]- B.Yadav, M. JAYNA, S. SURI, S. PHOGAT, R. MADAN, "Comparison of different final impression techniques for management of resorbed mandibular ridge: a case report", Case reports in dentistry, 2014.

[18]-K.M. Tan, M.T. Singer,R. Masri , C. F. DRISCOLL , "Modified fluid wax impression for a severely resorbed edentulous mandibular ridge", J Prosthet Dent,101(2009)279-28.

[19]- D. R. Burns, J. W. Unger, R. K. Elswick Jr., and D. A. Beck, "Prospective clinical evaluation of mandibular implant overdentures: part I-retention, stability, and tissue response", The Journal of Prosthetic Dentistry, 73(4) (1995) 354-363.

[20]- W.W.L Chee, Donovan TE. Polyvinyl siloxane impression materials, "A review of properties and techniques", The Journal of Prosthetic Dentistry,68(1992)728-32.

[21]- R. CRAIG, George,'S Restorative Dental Materials $12^{\text {th }}$ edition, Mosby, (2006) 283-303.

[22] T. E. Jacobson and A. J. Krol, "A contemporary review of the factors involved in complete dentures. Part II: stability", The Journal of Prosthetic Dentistry,49 (2) (1983)165-172.

[23]- J.MASSAD, W. DAVIS,J. THORNTON, "Improving the Stability of maxillardentures:the use of polyvinyl siloxsan impression materials for edentulous impressions", Dent Today,33(21)(2005)24-6.

[24]-R.Van Noort, Introduction To Dental Materials, 3rd -E-Book, Elsevier Health Sciences,(2007) 186-207.

[25]-P.Shah, , R.K. Singh, and P. Suwal, "Stability-A Key To Success Using Neutral Zone Technique: A Case Report", Guident, 13(9)(2020).

[26]- N. Singh, G. Kaur, and K. Kaur, "Comparison of two impression techniques for secondary impression for complete denture", Journal of Advanced Medical and Dental Sciences Research, 6 (2018)9 .

[27]- S.Dash, S. Gunjan , S. Monika , "Management of Mandibular Resorbed Ridges by Combining Two Impression Techniques: A Literature Review and Case Report", Indian Journal of Public Health Research \& Development, 10 (9)( 2019)1678-1683. 